
could overcome the limitations of incomplete data sources ${ }^{1}$.

Road traffic collisions in Malawi: Trends and patterns Malawi lacks a national pre-hospital system and few ambulance services and trained paramedics are available. Training first responders, developing an organized transportation and ambulance facilities, and setting up strategic roadside emergency trauma units is vital. However, a robust pre-hospital system should be also linked with a dedicated and satisfactory trauma care within the hospital system. For instance, our institution, Kamuzu Central Hospital in Lilongwe, has established a surgical residency to train general and orthopedic surgeons. It is our hope that the graduates will be able to stay in the country at district and regional hospitals to help offset the surgical workforce shortage.

The article "Road traffic collisions in Malawi: Trends and The article "Road traffic collisions in Malawi: Trends and
patterns of mortality on scene" is a retrospective evaluation patterns of mortality on scene" is a retrospective evaluation
of the road traffic deaths in Malawi from 2008-2012 using the National Road Safety Council of Malawi (NRSCM) database'. In this study the investigators sought to establish the trends and patterns in deaths at road traffic crashes and
the define the sociodemographic characteristics of the victims, all of which are critical for road traffic policy and emergency all of which are critical for road traffic policy and emergency
health services. Given the paucity of research into road health services. Given the paucity of research in.
trauma in Malawi, this study is important and timely.

As rightly noted by the investigators the NRSCM database is an independent but unreliable source for road traffic injury data due to major underreporting, especially for fatalities given that many die on route and on arrival to the hospital and are not reported, together with other cases where the police do not reach ${ }^{2,3}$. Recognizing this shortcoming, multiple data sources have been preferred for epidemiologic reviews 4 . Samuel et $\mathrm{al}^{2}$ recommend collating mortuary data for example from district hospitals with police and hospita data provides a better estimate for injury data. Data linkage in integrated injury surveillance is critical as it helps to more accurately assess: (1) injury burden and observe trends, an (2) related health costs and trauma prevention initiatives $s^{4,2}$.

However, for the purposes of this study which was to evaluate death at the crash scer better quantifying and understanding provides a basis for better quantifying and understanding report that data collected by the police generally include report that data collected by the police generally include
data on crash related factors such as accident type, type of vehicles, time of day, environmental hazards present and detailed information of crash victims, but have a limitation in ascertaining injury severity ${ }^{2,4}$. Results from this study provide crude death rates on road traffic injuries which are important in developing an overview of the road traffic injury burden. However, a prospective (follow up) design would help determine temporal factors related to road traffic injuries and death of victims and potentially indicate the window fo
emergency medicine from crash site to hospital admission. Finally, as we approach the end of the Global Plan for the Decade of Action for Road Safety 2011-2020 does not yet have a comprehensive or reliable national road trauma surveillance system which is essential for the evaluation of road traffic injury prevention strategies, the development of effective road safety policies and mobilizing national and international resources to manage a growing

yet largely ignored preventable cause of death and injury in Malawi. Therefore, setting up an active national road traum surveillance would help minimize such errors in estimation of injury and death burden as are present now. This study will no doubt be of real help in the quest for a reliable national oad trauma surveillance system.

References

1. Schlottmann F, Tyson AF, Cairns BA, Varela C, Charles AG. Road raffic collisions in Malaw . Frends and patterns of mortality on scen

2. Samuel JC, Sankhulani E, Qureshi JS, Baloyi P, Thupi C, Lee CN, tal. Under-reporting of road trafic mortality in developing countries: Application of a capture-recapture statistical model to refine mortality pone.003109

3. Dandona R, Kumar GA, Ameer A, Brahmananda G, Dandona L.

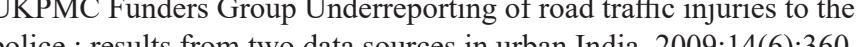
5. doi: 10.1136/ip 2008 019638

4. 4.

. Collaboration UNRS. Global plan for the Decade of Action for Road Safety 2011-2020. Geneva WHO [Internet]. 2011;25. Available intitle:Global+Plan+for+the+Decade+of + Action+for+Road+Safe $\mathrm{y}+2011-2020 \# 0$

\section{Authors Reply}

Francisco Schlottmann ${ }^{1}$, Anthony G. Charles ${ }^{1,2}$ . Department of Surgery, University of North Carolina, Chapel Hill,

Correspondance: fschlott@med.unc.edu

Dear Editor,

We wish to thank Manyozo et al for their comments. We agree that police data tend to underreport injuries and death due to poor traffic police response and follow up on injured victims (e.g. fatalities on route or upon arrival to the hospital). Unfortunately, many developing countries rely solely on police accident registries to estimate the burden of road traffic injuries. We believe adequate acquisition and interpretation of data is critical for planning interventions
Finally, the World Bank in concert with the Malawi government are about to establish a pre-hospital system strategically placed ambulance services with community workers trained as paramedics) along the M1 corridor from Blantyre to Lilongwe with coordination and communications system with the receiving district and central hospitals. As part of this effort, a longitudinal data collection system that the way to hospital

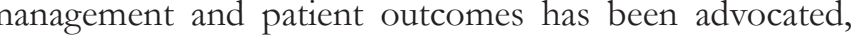
Reur group is actively involved in this effort.

\section{References}

1. Samuel JC, Sankhulani E, Qureshi JS, Baloyi P, Thupi C, Lee $\mathrm{CN}$, et al. Under-reporting of road traffic mortality in developing countries: application of a capture-recapture statistical model to refine pone.0031091 